\title{
The Application and Indications for Sentinel Lymph Node Biopsy in Pediatric Solid Tumors: Current Status and Future Directions
}

\author{
Nathan M. Hinkle1,2, Alpin D. Malkan², John A. Sandoval2* \\ ${ }^{1}$ Department of Surgery, St. Jude Children's Research Hospital, Memphis, USA \\ ${ }^{2}$ Department of Surgery, University of Tennessee Health Science Center, Memphis, USA \\ Email: ${ }^{\text {John.Sandoval@STJUDE.ORG }}$
}

Received 27 July 2014; revised 25 August 2014; accepted 19 September 2014

Copyright (C) 2014 by authors and Scientific Research Publishing Inc.

This work is licensed under the Creative Commons Attribution International License (CC BY). http://creativecommons.org/licenses/by/4.0/

\section{(c) (i) Open Access}

\begin{abstract}
Oncologic staging of many solid organ malignancies involves an understanding of how cancers spread via the lymphatic system, and ultimately may involve evaluation of the primary nodal drainage basin by performing a sentinel lymph node biopsy. In the adult population, there are well established indications for sentinel lymph node biopsy in diseases like melanoma and breast cancer. However, its use and relevance in the pediatric population is less defined. This review details the history and development of sentinel lymph node biopsy technique, advanced lymph node mapping techniques currently under investigation, and the applications of sentinel node biopsy towards childhood cancers.
\end{abstract}

\section{Keywords}

Sentinel Lymph Node Biopsy, Pediatric Melanoma, Spitz Nevus, Atypical Spitzoid Tumor, Spitzoid Melanoma, Rhabdomyosarcoma, Nonrhabdomyosarcoma, Soft Tissue Sarcoma, Breast Cancer

\section{Introduction}

The concept of the sentinel lymph node (SLN) as the initial site of lymphatic tumor spread, and therefore a predictor of metastases within the remainder of the nodal basin, was first introduced more than 50 years ago [1] [2]. The use of sentinel lymph node biopsy (SLNB) is widely accepted and considered standard of care for many

"Corresponding author.

How to cite this paper: Hinkle, N.M., Malkan, A.D. and Sandoval, J.A. (2014) The Application and Indications for Sentinel Lymph Node Biopsy in Pediatric Solid Tumors: Current Status and Future Directions. International Journal of Clinical Medicine, 5, 1130-1141. http://dx.doi.org/10.4236/ijcm.2014.518145 
adult malignancies, including melanoma [3]-[5], breast [6], colon [7] and vulvar cancer [8]. Its use in pediatric patients is limited but studies show the technique is pivotal in staging children with malignant melanoma [9]-[12]. Additionally, the application of SLNB can be useful in children who present with pigmented lesions such as atypical Spitz tumors and spitzoid melanomas which are not easy to classify as benign or malignant [13]. Another potential use for lymphatic mapping with SLNB in children is with soft tissue sarcomas and breast cancer. Several institutional experiences using SLNB in pediatric sarcomas have recently been published and demonstrated that SLNB is practical and may be useful in directing treatment of rhabdomyosarcoma (RMS). However, SLNB appears to be less useful in non-rhabdomyosarcoma soft tissue sarcoma (NRSTS) of the extremity, with only one study reporting positive SLNBs in patients with NRSTS [14]-[17]. As the data available on its application in children become more robust, the central role SLNB has helped surgeons avoid radical lymphadenectomies in node negative patients who would previously have undergone a more morbid operation with little benefit. In this article, we present the history and technique of SLNB, discuss the most relevant literature on clinical indications and results of its use in childhood cancer and lastly, provide a contemporary perspective on new technologies for identifying and analyzing the SLN.

\section{History}

Lymphatic spread of metastatic carcinoma was defined by the work of Gilchrist [18] and Zeidman [19] et al. in the mid-twentieth century. Their studies involved injecting various dyes, carbonaceous particles and cancer cells into the lymphatics of animal models. Systematic and reproducible dissemination of disease through the lymphatic system was shown and lymph nodes were found to be a barrier to distant metastases. Gould reported the first SLNB in a case series published in 1960 [2]. He described a total parotidectomy in 1951 where a normal appearing node sent for frozen section was found to contain metastatic tumor. Disease in the lymph node prompted Gould to perform a radical neck dissection in a case where he otherwise would not. Identifying this node, located at the confluence of the anterior and posterior facial vein, and frozen section histopathologic evaluation assisted in the surgical approach in terms of whether the patient required parotidectomy alone or the addition of an extensive neck dissection. Cabanas introduced lymphatic mapping with SLNB in the treatment of penile cancer [20]. However, the technique did not gain widespread use in oncologic resections until it was described by Morton et al. in malignant melanoma excisions [3]. SLNB was later adopted and modified for use in the management of a variety of other malignancies including uterine, thyroid, and breast cancers [21]-[23].

Initially, intraoperative SLN imaging was done using blue dye injected peritumorally. In the early 1990s, protocols using radio-isotopes and handheld gamma probes were developed for breast cancer [24] [25]. Radioisotopes were found to be very effective in assisting in the identification of SLNs. Dual mapping, the use of both blue dye and radio-isotopes, was first described in breast cancer by Albertini et al. [26]. Each technique was compared to dual-agent injection by McMasters et al. who found dual-agent injection had more successful localization and a lower false-negative rate than either modality alone [27].

In adults, melanoma and breast cancer are the two most common diseases for which lymphatic mapping and SLNB are performed. They are the basis for our discussion of SLNB rationale and technique. The sentinel node is the first node in the lymphatic drainage pathway from the primary tumor to its regional nodal basin. Defining the pathologic status of the sentinel node leads to more accurate staging. If the sentinel node is without disease this may spare patients unnecessary regional lymph node dissections and their associated morbidities [28].

With regard to melanoma, for example, node status is the most significant predictor of recurrence and survival with one-fifth of all patients presenting with nodal metastases. Node-positive patients have a five-year survival approximately $40 \%$ lower than patients without nodal involvement [29]. Ninety percent of melanoma patients present with no clinical evidence of nodal metastases and were previously referred to as clinical stage I (CS-I). Prior to the development of sentinel node techniques, CS-I patients often underwent elective lymph node dissections (ELND) as it was not possible to assess node status without removal of the entire regional node basin [3]. As the above numbers show, $80 \%$ of the patients subjected to an ELND received no therapeutic benefit but were subject to all the possible morbidity of the procedure.

\section{Sentinel Lymph Node Biopsy Technique}

Successful identification and subsequent assessment of a sentinel node for metastatic disease requires a multidisciplinary team. There is a significant learning curve to performing these procedures with consistent, repro- 
ducible, and accurate results [23]. Preoperative injection of radiolabeled tracer and lymphoscintigraphy are performed by the nuclear medicine physician. The surgeon must then identify any and all SLNs. Finally, the pathologist needs to correctly assess for the presence of metastatic disease in nodes identified [30]. Mistakes in any portion of the process can lead to inappropriate staging and subsequent failures in treatment.

Lymphoscintigraphy is helpful in assessing anomalous drainage patterns or lesions that may drain to more than one node basin [31]. Aberrant or unexpected drainage patterns usually involve lesions in the truncal midline, near Sappey's lines or in previously operated/irradiated fields [30]. These instances make preoperative imaging and assessment of the patient critical. Patients may require repositioning in the operating room to gain access to regional node basins of interest after addressing the primary lesion [28]. Patients undergo preoperative lymphoscintigraphy following injection with a radiolabeled tracer. Technetium-99m $\left({ }^{99 \mathrm{~m}} \mathrm{Tc}\right)$-labeled sulfur colloid or ${ }^{99 m}$ Tc-labeled trisulfide colloid are generally used with $0.5 \mathrm{mCi}$ or less and a volume less than $1 \mathrm{~cm}^{3}$ when imaging for melanoma [28]. Injections for cutaneous disease are usually intradermal and serial imaging is begun about 10 minutes after injection. All regional nodal basins at risk should be marked as well as in-transit nodes. Should imaging fail to show migration of radio-tracer after one hour, a second injection can be performed [30].

In-transit nodes, lymph nodes en route to major nodal basins proximal to the lesion are occasionally identified in melanoma cases. This emphasizes the importance of preoperative lymphoscintigraphy even in cases of primary malignancies in extremities. For cutaneous malignancies, surgical procedures should be completed within 6 to 8 hours of radiotracer injection as sentinel node activity will peak within 2 to 6 hours. Preoperative gamma probe evaluation allows the surgeon to assess the primary tumor site and look for in-transit nodes in the path to regional nodal basins prior to placing the patient under anesthesia or positioning in the operating room [28].

Vital blue dye in combination with radio-labeled tracer is often used in identifying sentinel nodes. Dye is injected into the dermis immediately adjacent to cutaneous malignancies like melanoma. For primary sites located in extremities, injections are made proximal to the lesion. Truncal lesions are injected circumferentially to assess all possible regional node beds it may drain into. Time needed to allow dye to disperse prior to sentinel node retrieval will vary based on the distance of regional node basin from the primary lesion and patient physiology [32]. This generally takes 5 to 10 minutes.

Incisions for SLNB should be made over hot spots found using a handheld gamma probe and made in line with possible incisions required for completion lymphadenectomies should the sentinel node return positive for metastatic disease [28]. Sentinel nodes are defined as any node with an ex vivo count to background ratio greater than 10:1; a blue node or blue-stained lymphatic channels leading up to a node; or nodes that are firm and palpable. Nodes are removed with as little trauma as possible and careful attention is used to ligate afferent and efferent lymphatic channels to prevent postoperative seroma formation [28]. Ex vivo counts should be recorded on all nodes removed. Any lymph node with a count more than $10 \%$ of the hottest node should also be removed and included as part of the sentinel node specimen [33]. The sentinel node bed should be probed once again for a final count to document all significant radiolabeled nodes were removed. Visual and manual inspections are then completed to remove all blue nodes, those with blue lymphatic channels leading up to them, and any grossly palpable nodes. After removal, it is up to the pathologist to assess nodes for signs of metastatic disease. In general, nodes are halved and then serially sectioned at no more than $2 \mathrm{~mm}$ slices [34]. Sections are initially evaluated by hematoxylin-eosin (H \& E) staining. Depending on the disease process being evaluated, immunohistochemical staining may also be done if $\mathrm{H} \& \mathrm{E}$ staining fails to show metastatic disease [35].

Complications related to sentinel node biopsy are relatively uncommon. These include allergic reactions to blue dye, motor nerve injury, wound infections, seroma, and post-biopsy lymphedema. Compared to patients undergoing completion lymph node dissection, sentinel node biopsies had a complication rate of $4.6 \%$ versus 23.2\% in the landmark Sunbelt Melanoma Trial [36]. Blue dyes injected during sentinel node biopsy are not completely benign. Isosulfan blue (ISB) and methylene blue (MB) are both used in mapping sentinel nodes [37]. MB is significantly cheaper and some experts say it is a safer and equally efficacious alternative to ISB dye [38]. ISB can cause erythema at the injection site, urticaria, hives, oropharyngeal edema, and even anaphylaxis. MB has a more benign profile but can cause skin necrosis with intradermal injection. Methylene blue has been reported to cause a handful of cases of anaphylactic shock one of which was noted in a 6-year-old healthy girl undergoing treatment for a Spitzoid tumor in our institution [39].

With regard to pregnancy, both ISB and MB are category $\mathrm{X}$ as neither have been tested for safety during pregnancy and should be avoided. The minimal amount of radiation imparted on the fetus by radio-labeled tracer for sentinel node biopsy was shown to be low and safe in pregnancy [40]. Long-term outcomes confirmed the 
benefit of sentinel node biopsy use in staging and treatment of melanoma with the Multicenter Selective Lymphadenectomy Trial (MSLT-1). The trial compared wide local excision (WLE) and sentinel node biopsy to WLE and close observation in intermediate-thickness melanomas. Positive sentinel nodes prompted immediate therapeutic lymph node dissection (TLND) compared to delayed TLND in the observation arm once clinically apparent nodes were identified. Patients with positive sentinel nodes that received immediate TLND had a 5-year and 10-year survival advantage over the observation arm [41].

\section{Advanced Mapping Techniques}

In addition to vital blue dyes and conventional radio-labeled tracers, technological advances in lymphatic mapping are moving the SLNB landscape forward. Hybrid tracers containing a dual radioactive and fluorescent label have been introduced to improve the accuracy of SLN biopsy. For example, Technetium-99m ${ }^{99 \mathrm{~m}} \mathrm{Tc}$ )-tilmanocept (Lymphoseek) is a macrophage, radiolabeled sugar that binds to mannose receptors in reticuloendothelial cells in sentinel lymph nodes. These novel tracers have shown superiority over blue dyes in Phase III clinical trials in adult breast cancer and melanoma [42]. Other technical developments include non-invasive imaging with near-infrared fluorescence using indocyanine green and agents that directly conjugate to cancer-targeting moieties [43].

\section{Application of SLNB Surgery in Pediatric Neoplasms}

The application of SLNB towards several types of cancer remains a clinically proven, minimally invasive technique, that may accurately and reliably identify the disease status in regional lymph nodes in adults [44]. For nearly two decades this important prognostic tool has evolved. It has been pivotal in the accurate staging of adult diseases [3], and potentially avoids a morbid, complete lymph node dissection if evidence of metastatic disease is not found [45]. SLNB has been used and evaluated in children primarily for cutaneous melanoma, atypical spitzoid tumors (AST) and spitzoid melanoma, and soft tissue sarcomas. The following sections incorporate a review of the pediatric literature summarizing the progress with regard to the role of SLNB in these specific, aforementioned, childhood cancers.

\section{Melanoma}

Melanoma in children is uncommon and for this reason the treatment algorithm continues to be extrapolated from the adult literature [46]. The National Cancer Institute [47], and National Comprehensive Cancer Network [48] recommend that lymphatic mapping and SLNB can be considered to assess the presence of occult metastasis in the regional lymph nodes of patients with primary melanomas larger than 1 to $4 \mathrm{~mm}$ (intermediate thickness) [49], however, performing SLNB in thin melanomas continues to be controversial [44] [50]. The value of a positive SLNB is based on identifying whether there is histological evidence of micrometastatic disease in the SLN in patients with no other evidence of metastatic disease [29] [41]. In adults, determining the lymph node status currently remains the single most important prognostic factor for intermediate thickness cutaneous melanoma and is the standard of care [51]. To ensure adequate staging and identification of the SLN, lymphatic mapping (lymphoscintigraphy) and removal of the SLN is recommended to precede wide excision of the primary melanoma [47]. Although higher rates of lymph node metastasis have been reported in pediatric melanoma patients, the prognostic value of SLNB has not been extensively studied. During the past decade there has been limited, yet increasing number of reports evaluating the role of SLNB in children and adolescents [11] [12] [14] [15] [52]-[59].

Indications for SLNB in pediatric and adolescent patients include the presence of lesions thicker than $1 \mathrm{~mm}$, or the presence of ulceration, or a Clark's level of invasion of IV or V in patients with lesion less than $1 \mathrm{~mm}$ [46] [51] [60]. Over the past decade reports of SLNB positivity in pediatric melanoma has ranged between $25 \%$ and 50\% [9] [11] [15] [45] [53] [55] [58] [60] [61] [63]. The prognostic value of SLNB for pediatric melanomas is supported based on the fact that patients with a positive SNLB had significantly worse recurrence-free survival, melanoma-specific survival [53] [54], and correlated with overall survival [64]. However, others have been unable to demonstrate a significant association between a positive SLNB and overall survival [65]. Despite higher rates of positive SLNB, children and adolescents have a lower incidence of recurrence and improved disease-free survival when compared to adults [45] [57] [66].

Ferrari et al. described a series of 54 patients with cutaneous melanoma collected by the Italian Rare Tumors 
in Pediatric Age Project [61]. They routinely adopted the use of SLNB according to the American Joint Committee on Cancer (AJCC) adult guidelines [51], and they found 42.3\% (14/33) had a positive SLN [61]. Parida et al. retrospectively found a 38\% (11/29) positive SLN rate, and an overall 96.5\% (28/29) first attempt success rate at identification of the SLN [9]. Gow et al. found 50\% (2/4) of patients had a positive SLN [15]. Han et al. found that $28.8 \%$ (17/59) had SLN positivity, were associated with significantly thicker lesions, and children with melanoma had higher rates of SLN metastases than adults with comparable melanomas [53]. HowmanGiles et al. demonstrated a SLNB positivity rate of 25.5\% (14/55). Patients less than 10 years of age tended to have thicker melanomas, and a higher SLNB positivity rate as compared to those aged greater 10 years (33\% vs. 17\% respectively) [10]. Livestro et al. demonstrated a 43.7\% (7/16) SLNB positivity rate and were associated with a median tumor thickness of $2.8 \mathrm{~mm}$ [67]. Raval et al. evaluated the National Cancer Data Base between 2003 and 2007, and identified 671 patients with cutaneous melanoma. SLNB was performed in 461 patients and 118 had a positive SLN. Patients less than 5 years of age represented the group with the highest likelihood of lymph node metastases [62].

The 2008 Surveillance, Epidemiology and End Results (SEER) database in pediatric and young adults melanoma demonstrated pediatric characteristics that were associated with SLN metastases included increasing thicknesss, ulceration, and nodular histology. It was also found that children who had melanoma thickness between $1.01 \mathrm{~mm}$ and $2.00 \mathrm{~mm}$ had SLN metastases more often than young adults (age 20 - 24). Children were more likely than young adults to have SLN metastases for all analyzed characteristics (ulceration, histology, thickness, sex, and primary site) [54]. Survival analyses showed that a positive SLNB was a poor prognostic factor in pediatric and young adult melanoma [54]. SLNB has a prognostic role for pediatric melanoma patients since lymph node metastases are seen at a higher rate within this population [53]. Recommendations of the AJCC Melanoma Staging Committee for SLNB in patients with clinically localized melanomas greater than 1 mm thickness, (and selectively with thinner high-risk lesions), should be offered SLNB [51]. SLNB has enhanced accurate staging in pediatric melanoma, resulting in improvements in stage-specific survival [45].

\section{Spitz Nevi, Atypical Spitzoid Neoplasm and Spitzoid Melanoma}

Spitz nevi (SN) are a type of benign melanocytic tumor that may grossly and histologically mimic melanoma [58]. Another type of skin lesion known as atypical spitzoid neoplasms (ASN) are challenging to distinguish from melanoma [68] [69]. ASNs present a diagnostic dilemma because of a confusing combination of histologic qualities making it difficult to classify as benign (SN) or malignant (spitzoid melanoma) [70] [71]. The extreme variant, known as spitzoid melanoma (SM), has been defined as a rare melanoma subtype which shares many histopathologic features with spitz nevi and is one of the most difficult lesions to diagnose in dermatopathology [69]-[73].

Despite the fact that there is no single set of criteria that can distinguish ASNs from melanoma with total certainty [74], anxiety regarding the malignant potential or mis-diagnosis of ASNs has led to aggressive diagnostic and treatment procedures in children [74]. As a modality to distinguish ASNs from SN, the presence of micrometastasis in the SLN was initially proposed as a useful adjunct allowing for histologic analysis based on the premise that only melanoma will metastasize to the SLN [58] [75] [76]. However, this may confer a misdiagnosis of melanoma [58] since the use of metastasis as the only diagnostic criteria for malignancy is thought to lead to an overestimation of their biological aggressiveness [73].

SM may develop lymph node metastasis without further progression, or widespread metastasis and fatal outcome [73]. Therefore, the role of SLNB is of significant concern. The premise that the SLNB status may provide useful information and insight that may help better assess the true biologic potential of these tumors and allow for better counseling and subsequent therapy [75] [77] has yielded mixed results. Studies have both supported [78]-[80] and refuted [81] the use of SLNB for prognostic purposes when malignant melanoma cannot be entirely ruled out. Pathologists have cautioned against classifying cutaneous melanocytic tumors based on SLN alone [82] [83]. Spatz et al. identified factors predictive of metastasis which included age greater than 10 years, ulceration, extension into the subcutaneous fat, diameter greater than $10 \mathrm{~mm}$, and more than 6 mitosis per $\mathrm{mm}^{2}$ [84]. SLN status in patients with ASNs and SM may not have the same prognostic predictive value as in patients with conventional melanoma [70] [76] [77] [80] [82] [83] [85]-[89].

Paradela et al. demonstrated a SLNB positive rate of 56\% (14/25) in patients with SM. They observed that SM had poorer prognostic factors such as higher Breslow thickness, mitotic rate, and metastases, but the mortal- 
ity rate trend was lower in this group as compared to the non-spitzoid melanoma group (5.9\% vs 12\%) [73]. Better long-term outcomes in patients with ASNs or SM and positive SLN have been reported as compared to conventional melanomas [70] [76] [77] [90]. Cerrato et al. treated 29 patients using excision with clear surgical margins, had favorable outcomes, and demonstrated that SLNB is not warranted in the routine management of pediatric ASNs [74]. Parida et al retrospectively found that patients with ASNs and SMs had a $66.7 \%(2 / 3)$ and 33.3\% (1/3) positive SLN rate, respectively [9]. Han et al. showed that 33.3\% (1/3) of patients with SM were SLN positive [53]. Hung et al. demonstrated a series of patients with either ASNs and SM that underwent SLNB. The numbers of pediatric and young adult patients with ASN and SM SLNB positivity were 50\% (3/6) and $57.1 \%(4 / 7)$, respectively [91]. With all patients combined there was a $26 \%$ and 35\% SLN positivity rate in ASNs and conventional melanomas. Ludgate et al. demonstrated a high rate of SLNB positivity (47\%) in patients with ASNs [77]. Additionally, all SLN positive ASN patients were disease free with a median follow up of 43.8 months [77].

AST frequently involves regional lymph nodes in up to 50\% of patients [76] [77] [80] [87] [88] [92]. The clinical meaning of intraparenchymal SLN deposits is debated [93], with consideration of these features as unhelpful in determining the true biological potential of malignancy in these lesions [93] [94], and associated patient death is extremely rare [91]. Although SLNB continues to be an option for these patients since these lesions harbor metastatic potential, the result remains unclear as to whether this is a poor prognostic marker as in the case of melanoma. Counseling patients and families regarding the potential risks and benefits of SLNB in ASNs is necessary since they do not appear to behave like conventional melanomas [77]. It is only with long-term prospective studies that the true risk of malignancy will become more clear. Conversely, the recommendations and treatment modality for SM is similar to adult melanoma with regard to excision and timing of SLNB.

\section{Soft Tissue Sarcomas}

Soft tissue sarcomas (STS) are uncommon malignancies [95] and the discovery in children is even more rare [96]. STS may metastasize and most commonly develops in the lung. However, in the natural history of STS, dissemination to regional lymph nodes is not common [97]-[102]. Certain histologic subtypes including synovial sarcoma, epithelioid sarcoma, RMS, angiosarcoma, and clear cell sarcoma (CCS) may have a higher rate of nodal metastasis [98] [102]-[104]. Pediatric sarcomas [9] [14]-[17] [105] [106], and to a much lesser extent, non-rhabdomyosarcoma soft tissue sarcoma (NRSTS) have received attention with regard to lymph node evaluation in the form of SLNB [16] [17] [105].

De Corti et al. reported on 17 children with STS of the extremities of which 2 had positive SLNB (alveolar RMS and undifferentiated sarcoma) [16]. They found SLNB to be technically feasible, reliable, and without complications. Kayton et al. found SLN positivity in 1/9 RMS, and none of the patients with CCS, epithelioid sarcoma, fibrosarcoma, synovial sarcoma or alveolar soft part sarcoma [17]. Alcorn et al. reviewed eight patients that underwent SLNB for STS and found 25\% (2/8) of RMS were positive. The remaining patients (2 epithelioid sarcoma, 1 synovial sarcoma, 3 RMS) were SLN negative. They attempted to correlate those with SLNB positivity and computed tomography and/or positron emission tomography imaging. However, they found that imaging may not be sufficient to determine the lymph node status of pediatric patients with STS [96]. Andreou et al. evaluated SLNB positivity in patients with synovial sarcoma, CCS, epithelioid sarcoma, and RMS], and concluded that this modality is an important diagnostic tool for patients with CCS, who have a high rate of clinically occult regional lymph node metastasis at diagnosis [97]. Maduekwe et al. evaluated 29 patients with STS, and only one patient with synovial sarcoma had a positive SLNB. They found that SLNB in STS was not clinically useful in patients with localized synovial, epithelioid, or clear cell sarcoma [95].

Despite the prognosis for a child or adolescent with RMS being related to the age of the patient, site of origin, tumor size (widest diameter), resectability, presence of metastases, number of metastatic sites or tissues involved, presence or absence of regional lymph node involvement, histopathologic subtype (alveolar vs. embryonal), as well as unique biological characteristics of rhabdomyosarcoma tumor cells [107], data to support the role of SLNB in staging is extremely limited. Since regional lymph node metastases are unusual in NRSTS except in epithelioid and CCS [108], data is also limited to support the use of SLNB.

\section{Breast Cancer}

Male breast cancer is a rare but increasingly prevalent disease in adults [109]. To our knowledge this has not been reported in male children or adolescents. Flynn et al. demonstrated a SLNB positivity rate of 49\% (37/76) 
and demonstrated that SLNB is successful and accurate in male breast cancer patients [109]. Kayton et al. reported 5 patients under the age of 21 who underwent SLN for either invasive ductal carcinoma or juvenile secretory carcinoma. All five were females, two had positive SLNB with a diagnosis of invasive ductal carcinoma [17]. The application of SLNB seems theoretically appropriate towards the application in children with breast cancer, however, its rarity and lack of data do not justify such a recommendation.

\section{Conclusion}

Although SLNB has been supported as a pivotal part of staging pediatric cancers, and the technical feasibility has been demonstrated [11] [14] [58] [59] [110], the procedure can have dramatic consequences such as wound infection and lymphedema. For pediatric melanoma SLNB complications were seen in 52\% of inguinal dissection, $17.1 \%$ of axillary dissection, and $0 \%$ in cervical dissection [111]. There is abundant literature regarding the safety and feasibility of performing SLNB in adults. Over the past decade this technique has been applied to pediatric melanoma, atypical spitzoid neoplasm, spitzoid melanoma, RMS, NRSTS, and breast cancer. Despite several studies demonstrating that SLNB is a safe technique in children, there clearly is a lack of evidence supporting its universal use in treatment algorithms for these rare pathologies in the pediatric population.

\section{References}

[1] Seaman, W.B. and Powers, W.E. (1955) Studies on the Distribution of Radioactive Colloidal Gold in Regional Lymph Nodes Containing Cancer. Cancer, 8, 1044-1046.

http://dx.doi.org/10.1002/1097-0142(1955)8:5<1044::AID-CNCR2820080530>3.0.CO;2-6

[2] Gould, E.A., Winship, T., Philbin, P.H. and Kerr, H.H. (1960) Observations on a "Sentinel Node" in Cancer of the Parotid. Cancer, 13, 77-78. http://dx.doi.org/10.1002/1097-0142(196001/02)13:1<77::AID-CNCR2820130114>3.0.CO;2-D

[3] Morton, D.L., Wen, D.R., Wong, J.H., Economou, J.S., Cagle, L.A., Storm, F.K., et al. (1992) Technical Details of Intraoperative Lymphatic Mapping for Early Stage Melanoma. Archives of Surgery, 127, 392-399. http://dx.doi.org/10.1001/archsurg.1992.01420040034005

[4] Morton, D.L., Thompson, J.F., Essner, R., Elashoff, R., Stern, S.L., Nieweg, O.E., et al. (1999) Validation of the Accuracy of Intraoperative Lymphatic Mapping and Sentinel Lymphadenectomy for Early-Stage Melanoma: A Multicenter Trial. Multicenter Selective Lymphadenectomy Trial Group. Annals of Surgery, 230, 453-463. http://dx.doi.org/10.1097/00000658-199910000-00001

[5] Pijpers, R., Collet, G.J., Meijer, S. and Hoekstra, O.S. (1995) The Impact of Dynamic Lymphoscintigraphy and Gamma Probe Guidance on Sentinel Node Biopsy in Melanoma. European Journal of Nuclear Medicine and Molecular Imaging, 22, 1238-1241. http://dx.doi.org/10.1007/BF00801606

[6] Giuliano, A.E., Dale, P.S., Turner, R.R., Morton, D.L., Evans, S.W. and Krasne, D.L. (1995) Improved Axillary Staging of Breast Cancer with Sentinel Lymphadenectomy. Annals of Surgery, 222, 394-399. http://dx.doi.org/10.1097/00000658-199509000-00016

[7] Hamy, A., Curtet, C., Paineau, J., Chatal, J.F. and Visset, J. (1995) Feasibility of Radioimmunoguided Surgery of Colorectal Carcinoma Using Indium 111 CEA Specific Antibody and Simulation with a Phantom Using 2 Steps Targetting with Bispecific Antibody. Tumori, 81, 103-106.

[8] Levenback, C., Burke, T.W., Morris, M., Malpica, A., Lucas, K.R. and Gershenson, D.M. (1995) Potential Applications of Intraoperative Lymphatic Mapping in Vulvar Cancer. Gynecologic Oncology, 59, 216-220. http://dx.doi.org/10.1006/gyno.1995.0011

[9] Parida, L., Morrisson, G.T., Shammas, A., Hossain, A.K., McCarville, M.B., Gerstle, J.T., et al. (2012) Role of Lymphoscintigraphy and Sentinel Lymph Node Biopsy in the Management of Pediatric Melanoma and Sarcoma. Pediatric Surgery International, 28, 571-578. http://dx.doi.org/10.1007/s00383-012-3066-X

[10] Howman-Giles, R., Shaw, H.M., Scolyer, R.A., Murali, R., Wilmott, J., McCarthy, S.W., et al. (2010) Sentinel Lymph Node Biopsy in Pediatric and Adolescent Cutaneous Melanoma Patients. Annals of Surgical Oncology, 17, 138-143. http://dx.doi.org/10.1245/s10434-009-0657-4

[11] Toro, J., Ranieri, J.M., Havlik, R.J., Coleman III, J.J. and Wagner, J.D. (2003) Sentinel Lymph Node Biopsy in Children and Adolescents with Malignant Melanoma. Journal of Pediatric Surgery, 38, 1063-1065. http://dx.doi.org/10.1016/S0022-3468(03)00193-3

[12] Gibbs, P., Moore, A., Robinson, W., Walsh, P., Golitz, L. and Gonzalez, R. (2000) Pediatric Melanoma: Are Recent Advances in the Management of Adult Melanoma Relevant to the Pediatric Population. Journal of Pediatric Hematology/Oncology, 22, 428-432. http://dx.doi.org/10.1097/00043426-200009000-00008 
[13] Kayton, M.L. and La Quaglia, M.P. (2008) Sentinel Node Biopsy for Melanocytic Tumors in Children. Seminars in Diagnostic Pathology, 25, 95-99. http://dx.doi.org/10.1053/j.semdp.2008.05.001

[14] Neville, H.L., Andrassy, R.J., Lally, K.P., Corpron, C. and Ross, M.I. (2000) Lymphatic Mapping with Sentinel Node Biopsy in Pediatric Patients. Journal of Pediatric Surgery, 35, 961-964. http://dx.doi.org/10.1053/jpsu.2000.6936

[15] Gow, K.W., Rapkin, L.B., Olson, T.A., Durham, M.M., Wyly, B. and Shehata, B.M. (2008) Sentinel Lymph Node Biopsy in the Pediatric Population. Journal of Pediatric Surgery, 43, 2193-2198. http://dx.doi.org/10.1016/j.jpedsurg.2008.08.063

[16] De Corti, F., Dall’Igna, P., Bisogno, G., Casara, D., Rossi, C.R., Foletto, M., et al. (2009) Sentinel Node Biopsy in Pediatric Soft Tissue Sarcomas of Extremities. Pediatric Blood \& Cancer, 52, 51-54. http://dx.doi.org/10.1002/pbc.21777

[17] Kayton, M.L., Delgado, R., Busam, K., Cody III, H.S., Athanasian, E.A., Coit, D. and La Quaglia, M.P. (2008) Experience with 31 Sentinel Lymph Node Biopsies for Sarcomas and Carcinomas in Pediatric Patients. Cancer, 112, 20522059. http://dx.doi.org/10.1002/cncr.23403

[18] Gilchrist, R.K. (1940) Fundamental Factors Governing Lymphatic of Carcinoma. Annals of Surgery, 111, 630-639. http://dx.doi.org/10.1097/00000658-194004000-00014

[19] Zeidman, I. and Buss, J.M. (1954) Experimental Studies on the Spread of Cancer in the Lymphatic System. I. Effectiveness of the Lymph Node as a Barrier to the Passage of Embolic Tumor Cells. Cancer Research, 14, 403-405.

[20] Cabanas, R.M. (1977) An Approach for the Treatment of Penile Carcinoma. Cancer, 39, 456-466. http://dx.doi.org/10.1002/1097-0142(197702)39:2<456::AID-CNCR2820390214>3.0.CO;2-I

[21] Burke, T.W., Levenback, C., Tornos, C., Morris, M., Wharton, J.T. and Gershenson, D.M. (1996) Intraabdominal Lymphatic Mapping to Direct Selective Pelvic and Paraaortic Lymphadenectomy in Women with High-Risk Endometrial Cancer: Results of a Pilot Study. Gynecologic Oncology, 62, 169-173. http://dx.doi.org/10.1006/gyno.1996.0211

[22] Kelemen, P.R., Van Herle, A.J. and Giuliano, A.E. (1998) Sentinel Lymphadenectomy in Thyroid Malignant Neoplasms. JAMA Surgery, 133, 288-292. http://dx.doi.org/10.1001/archsurg.133.3.288

[23] Giuliano, A.E., Kirgan, D.M., Guenther, J.M. and Morton, D.L. (1994) Lymphatic Mapping and Sentinel Lymphadenectomy for Breast Cancer. Annals of Surgery, 220, 391-398. http://dx.doi.org/10.1097/00000658-199409000-00015

[24] Krag, D.N., Weaver, D.L., Alex, J.C. and Fairbank, J.T. (1993) Surgical Resection and Radiolocalization of the Sentinel Lymph Node in Breast Cancer Using a Gamma Probe. Surgical Oncology, 2, 335-339. http://dx.doi.org/10.1016/0960-7404(93)90064-6

[25] Krag, D., Weaver, D., Ashikaga, T., Moffat, F., Klimberg, V.S., Shriver, C., et al. (1998) The Sentinel Node in Breast Cancer-A Multicenter Validation Study. New England Journal of Medicine, 339, 941-946. http://dx.doi.org/10.1056/NEJM199810013391401

[26] Albertini, J.J., Lyman, G.H., Cox, C., Yeatman, T., Balducci, L., Ku, N., et al. (1996) Lymphatic Mapping and Sentinel Node Biopsy in the Patient with Breast Cancer. JAMA, 276, 1818-1822. http://dx.doi.org/10.1001/jama.1996.03540220042028

[27] Mcmasters, K.M., Tuttle, T.M., Carlson, D.J., Brown, C.M., Noyes, R.D., Glaser, R.L., et al. (2000) Sentinel Lymph Node Biopsy for Breast Cancer: A Suitable Alternative to Routine Axillary Dissection in Multi-Institutional Practice When Optimal Technique Is Used. Journal of Clinical Oncology, 18, 2560-2566.

[28] Stanley, A., William, C., Herbert, C. and Gregory, J. (2014) Lymphatic Mapping and Sentinel Nodes Biopsy. In: Stanley, A., William, C., Herbert, C. and Gregory, J., Eds., ACS Surgery: Principles and Practice, B.C. Decker, Inc., Ontario.

[29] Morton, D.L., Cochran, A.J., Thompson, J.F., Elashoff, R., Essner, R., Glass, E.C., et al. (2005) Sentinel Node Biopsy for Early-Stage Melanoma: Accuracy and Morbidity in MSLT-I, an International Multicenter Trial. Annals of Surgery, 242, 302-311.

[30] Thompson, J.F. and Uren, R.F. (2005) Lymphatic Mapping in Management of Patients with Primary Cutaneous Melanoma. Lancet Oncology, 6, 877-885. http://dx.doi.org/10.1016/S1470-2045(05)70423-X

[31] Vitali, G.C., Trifiro, G., Zonta, M., Pennacchioli, E., Santoro, L., Travaini, L.L., Barberis, M. and Testori, A. (2014) Lymphoscintigraphy in Clinical Routine Practice: Reproducibility and Accuracy in Melanoma Patients with a LongTerm Follow-Up. European Journal of Surgical Oncology, 40, 55-60. http://dx.doi.org/10.1016/j.ejso.2013.09.003

[32] Morton, D.L. (1997) Sentinel Lymphadenectomy for Patients with Clinical Stage I Melanoma. Journal of Surgical Oncology, 66, 267-269. http://dx.doi.org/10.1002/(SICI)1096-9098(199712)66:4<267::AID-JSO9>3.0.CO;2-9

[33] Camp, M. and Smith, B. (2013) Lymphatic Mapping and Sentinel Lymphadenectomy. In: Cameron, J. and Cameron, A., Eds., Current Surgical Therapy, Saunders, 592-595.

[34] Stitzenberg, K.B., Calvo, B.F., Iacocca, M.V., Neelon, B.H., Sansbury, L.B., Dressler, L.G. and Ollila, D.W. (2002) Cytokeratin Immunohistochemical Validation of the Sentinel Node Hypothesis in Patients with Breast Cancer. Ameri- 
can Journal of Clinical Pathology, 117, 729-737.

[35] Cochran, A. (2012) Sentinel Lymph Node Biopsies. In: Calonje, E., Brenn, T. and Lazar, A., Eds., Mckee’s Pathology of the Skin, with Clinical Correlations, Saunders, 1296-1309.

[36] Wrightson, W.R., Wong, S.L., Edwards, M.J., Chao, C., Reintgen, D.S., Ross, M.I., et al. (2003) Complications Associated with Sentinel Lymph Node Biopsy for Melanoma. Annals of Surgical Oncology, 10, 676-680. http://dx.doi.org/10.1245/ASO.2003.10.001

[37] Simmons, R., Thevarajah, S., Brennan, M.B., Christos, P. and Osborne, M. (2003) Methylene Blue Dye as an Alternative to Isosulfan Blue Dye for Sentinel Lymph Node Localization. Annals of Surgical Oncology, 10, 242-247. http://dx.doi.org/10.1245/ASO.2003.04.021

[38] Aydogan, F., Celik, V., Uras, C., Salihoglu, Z. and Topuz, U. (2008) A Comparison of the Adverse Reactions Associated with Isosulfan Blue versus Methylene Blue Dye in Sentinel Lymph Node Biopsy for Breast Cancer. American Journal of Surgery, 195, 277-278. http://dx.doi.org/10.1016/j.amjsurg.2007.03.008

[39] Wahid, F., Malkan, A., Pappo, A., Wright, B., Adefeyisan, S. and Sandoval, J. (2014) Severe Anaphylactic Shock Due to Methylene Blue Dye. Journal of Pediatric Surgery Case Reports, 2, 117-118. http://dx.doi.org/10.1016/j.epsc.2014.02.009

[40] Spanheimer, P.M., Graham, M.M., Sugg, S.L., Scott-Conner, C.E. and Weigel, R.J. (2009) Measurement of Uterine Radiation Exposure from Lymphoscintigraphy Indicates Safety of Sentinel Lymph Node Biopsy during Pregnancy. Annals of Surgical Oncology, 16, 1143-1147. http://dx.doi.org/10.1245/s10434-009-0390-z

[41] Morton, D.L., Thompson, J.F., Cochran, A.J., Mozzillo, N., Elashoff, R., Essner, R., et al. (2006) Sentinel-Node Biopsy or Nodal Observation in Melanoma. New England Journal of Medicine, 355, 1307-1317. http://dx.doi.org/10.1056/NEJMoa060992

[42] Tausch, C., Baege, A. and Rageth, C. (2014) Mapping Lymph Nodes in Cancer Management-Role of ${ }^{99 \mathrm{~m}}$ Tc-Tilmanocept Injection. OncoTargets and Therapy, 7, 1151-1158. http://dx.doi.org/10.2147/OTT.S50394

[43] Sevick-Muraca, E.M., Kwon, S. and Rasmussen, J.C. (2014) Emerging Lymphatic Imaging Technologies for Mouse and Man. Journal of Clinical Investigation, 124, 905-914. http://dx.doi.org/10.1172/JCI71612

[44] Sondak, V.K., Wong, S.L., Gershenwald, J.E. and Thompson, J.F. (2013) Evidence-Based Clinical Practice Guidelines on the Use of Sentinel Lymph Node Biopsy in Melanoma. American Society of Clinical Oncology Educational Book, E320.

[45] Aldrink, J.H., Selim, M.A., Diesen, D.L., Johnson, J., Pruitt, S.K., Tyler, D.S. and Seigler, H.F. (2009) Pediatric Melanoma: A Single-Institution Experience of 150 Patients. Journal of Pediatric Surgery, 44, 1514-1521. http://dx.doi.org/10.1016/j.jpedsurg.2008.12.003

[46] Pappo, A.S. (2003) Melanoma in Children and Adolescents. European Journal of Cancer, 39, 2651-2661. http://dx.doi.org/10.1016/j.ejca.2003.06.001

[47] National Cancer Institute at the National Institutes of Health. Melanoma Treatment (PDQ ${ }^{\circledR}$ ). http://www.cancer.gov

[48] National Comprehensive Cancer Network. Melanoma. www.nccn.org

[49] Wong, S.L., Balch, C.M., Hurley, P., Agarwala, S.S., Akhurst, T.J., Cochran, A., et al. (2012) Sentinel Lymph Node Biopsy for Melanoma: American Society of Clinical Oncology and Society of Surgical Oncology Joint Clinical Practice Guideline. Journal of Clinical Oncology, 30, 2912-2918. http://dx.doi.org/10.1200/JCO.2011.40.3519

[50] Mozzillo, N., Pennacchioli, E., Gandini, S., Caracò, C., Crispo, A., Botti, G., et al. (2013) Sentinel Node Biopsy in Thin and Thick Melanoma. Annals of Surgical Oncology, 20, 2780-2786. http://dx.doi.org/10.1245/s10434-012-2826-0

[51] Balch, C.M., Gershenwald, J.E., Soong, S.J., Thompson, J.F., Atkins, M.B., Byrd, D.R., et al. (2009) Final Version of 2009 AJCC Melanoma Staging and Classification. Journal of Clinical Oncology, 27, 6199-6206. http://dx.doi.org/10.1200/JCO.2009.23.4799

[52] Han, D., Zager, J.S., Han, G., Marzban, S.S., Puleo, C.A., Sarnaik, A.A., Reed, D., Messina, J.L. and Sondak, V.K. (2012) The Unique Clinical Characteristics of Melanoma Diagnosed in Children. Annals of Surgical Oncology, 19, 3888-3895. http://dx.doi.org/10.1245/s10434-012-2554-5

[53] Han, D., Yu, D., Zhao, X., Marzban, S.S., Messina, J.L., Gonzalez, R.J., et al. (2012) Sentinel Node Biopsy Is Indicated for Thin Melanomas $\geq 0.76 \mathrm{~mm}$. Annals of Surgical Oncology, 19, 3335-3342. http://dx.doi.org/10.1245/s10434-012-2469-1

[54] Mu, E., Lange, J.R. and Strouse, J.J. (2012) Comparison of the Use and Results of Sentinel Lymph Node Biopsy in Children and Young Adults with Melanoma. Cancer, 118, 2700-2707. http://dx.doi.org/10.1002/cncr.26578

[55] Bütter, A., Hui, T., Chapdelaine, J., Beaunoyer, M., Flageole, H. and Bouchard, S. (2005) Melanoma in Children and the Use of Sentinel Lymph Node Biopsy. Journal of Pediatric Surgery, 40, 797-800. http://dx.doi.org/10.1016/j.jpedsurg.2005.01.045 
[56] Shah, N.C., Gerstle, J.T., Stuart, M., Winter, C. and Pappo, A. (2006) Use of Sentinel Lymph Node Biopsy and HighDose Interferon in Pediatric Patients with High-Risk Melanoma: The Hospital for Sick Children Experience. Journal of Pediatric Hematology/Oncology, 28, 496-500. http://dx.doi.org/10.1097/01.mph.0000212973.28996.e4

[57] Roaten, J.B., Partrick, D.A., Bensard, D., Pearlman, N., Gonzalez, R., Fitzpatrick, J. and Mccarter, M.D. (2005) Survival in Sentinel Lymph Node-Positive Pediatric Melanoma. Journal of Pediatric Surgery, 40, 988-992. http://dx.doi.org/10.1016/j.jpedsurg.2005.03.014

[58] Roaten, J.B., Partrick, D.A., Pearlman, N., Gonzalez, R.J., Gonzalez, R. and McCarter, M.D. (2005) Sentinel Lymph Node Biopsy for Melanoma and Other Melanocytic Tumors in Adolescents. Journal of Pediatric Surgery, 40, $232-235$. http://dx.doi.org/10.1016/j.jpedsurg.2004.09.022

[59] Kogut, K.A., Fleming, M., Pappo, A.S. and Schropp, K.P. (2000) Sentinel Lymph Node Biopsy for Melanoma in Young Children. Journal of Pediatric Surgery, 35, 965-966. http://dx.doi.org/10.1053/jpsu.2000.6937

[60] Topar, G. and Zelger, B. (2007) Assessment of Value of the Sentinel Lymph Node Biopsy in Melanoma in Children and Adolescents and Applicability of Subcutaneous Infusion Anesthesia. Journal of Pediatric Surgery, 42, 1716-1720. http://dx.doi.org/10.1016/j.jpedsurg.2007.05.028

[61] Ferrari, A., Bisogno, G., Cecchetto, G., Santinami, M., Maurichi, A., Bono, A., et al. (2014) Cutaneous Melanoma in Children and Adolescents: The Italian Rare Tumors in Pediatric Age Project Experience. Journal of Pediatrics, 164, 376-382.

[62] Raval, M.V., Bilimoria, K.Y., Bentrem, D.J., Stewart, A.K., Ko, C.Y., Reynolds, M. and Wayne, J.D. (2010) Use of Sentinel Lymph Node Biopsy for Melanoma in Children and Adolescents. Journal of Surgical Oncology, 102, 634-639. http://dx.doi.org/10.1002/jso.21683

[63] Strouse, J.J., Fears, T.R., Tucker, M.A. and Wayne, A.S. (2005) Pediatric Melanoma: Risk Factor and Survival Analysis of the Surveillance, Epidemiology and End Results Database. Journal of Clinical Oncology, 23, 4735-4741. http://dx.doi.org/10.1200/JCO.2005.02.899

[64] Moore-Olufemi, S., Herzog, C., Warneke, C., Gershenwald, J.E., Mansfield, P., Ross, M., Prieto, V., Lally, K.P. and Hayes-Jordan, A. (2011) Outcomes in Pediatric Melanoma: Comparing Prepubertal to Adolescent Pediatric Patients. Annals of Surgery, 253, 1211-1215. http://dx.doi.org/10.1097/SLA.0b013e318217e852

[65] Paradela, S., Fonseca, E., Pita-Fernández, S., Kantrow, S.M., Diwan, A.H., Herzog, C. and Prieto, V.G. (2010) Prognostic Factors for Melanoma in Children and Adolescents: A Clinicopathologic, Single-Center Study of 137 Patients. Cancer, 116, 4334-4344.

[66] Chao, C., Martin, R.C., Ross, M.I., Reintgen, D.S., Edwards, M.J., Noyes, R.D., et al. (2004) Correlation between Prognostic Factors and Increasing Age in Melanoma. Annals of Surgical Oncology, 11, 259-264. http://dx.doi.org/10.1245/ASO.2004.04.015

[67] Livestro, D.P., Kaine, E.M., Michaelson, J.S., Mihm, M.C., Haluska, F.G., Muzikansky, A., Sober, A.J. and Tanabe, K.K. (2007) Melanoma in the Young: Differences and Similarities with Adult Melanoma: A Case-Matched Controlled Analysis. Cancer, 110, 614-624. http://dx.doi.org/10.1002/cncr.22818

[68] Crotty, K.A., Scolyer, R.A., Li, L., Palmer, A.A., Wang, L. and Mccarthy, S.W. (2002) Spitz Naevus versus Spitzoid Melanoma: When and How Can They Be Distinguished? Pathology, 34, 6-12. http://dx.doi.org/10.1080/00313020120111212-1

[69] Barnhill, R.L., Argenyi, Z.B., From, L., Glass, L.F., Maize, J.C., Mihm Jr., M.C., Rabkin, M.S., Ronan, S.G., White, W.L. and Piepkorn, M. (1999) Atypical Spitz Nevi/Tumors: Lack of Consensus for Diagnosis, Discrimination from Melanoma, and Prediction of Outcome. Human Pathology, 30, 513-520. http://dx.doi.org/10.1016/S0046-8177(99)90193-4

[70] Tom, W.L., Hsu, J.W., Eichenfield, L.F. and Friedlander, S.F. (2011) Pediatric “STUMP” Lesions: Evaluation and Management of Difficult Atypical Spitzoid Lesions in Children. Journal of the American Academy of Dermatology, 64, 559-572. http://dx.doi.org/10.1016/j.jaad.2009.12.063

[71] Miteva, M. and Lazova, R. (2010) Spitz Nevus and Atypical Spitzoid Neoplasm. Seminars in Cutaneous Medicine and Surgery, 29, 165-173. http://dx.doi.org/10.1016/j.sder.2010.06.003

[72] Wititsuwannakul, J., Mason, A.R., Klump, V.R. and Lazova, R. (2013) Neuropilin-2 as a Useful Marker in the Differentiation between Spitzoid Malignant Melanoma and Spitz Nevus. Journal of the American Academy of Dermatology, 68, 129-137. http://dx.doi.org/10.1016/j.jaad.2012.07.009

[73] Paradela, S., Fonseca, E., Pita-Fernández, S. and Prieto, V.G. (2013) Spitzoid and Non-Spitzoid Melanoma in Children: A Prognostic Comparative Study. Journal of the European Academy of Dermatology and Venereology, 27, 1214-1221.

[74] Cerrato, F., Wallins, J.S., Webb, M.L., Mccarty, E.R., Schmidt, B.A. and Labow, B.I. (2012) Outcomes in Pediatric Atypical Spitz Tumors Treated without Sentinel Lymph Node Biopsy. Pediatric Dermatology, 29, 448-453. http://dx.doi.org/10.1111/j.1525-1470.2011.01699.x 
[75] Kelley, S.W. and Cockerell, C.J. (2000) Sentinel Lymph Node Biopsy as an Adjunct to Management of Histologically Difficult to Diagnose Melanocytic Lesions: A Proposal. Journal of the American Academy of Dermatology, 42, 527530. http://dx.doi.org/10.1016/S0190-9622(00)90236-6

[76] Lohmann, C.M., Iversen, K., Jungbluth, A.A., Berwick, M. and Busam, K.J. (2002) Expression of Melanocyte Differentiation Antigens and Ki-67 in Nodal Nevi and Comparison of Ki-67 Expression with Metastatic Melanoma. American Journal of Surgical Pathology, 26, 1351-1357. http://dx.doi.org/10.1097/00000478-200210000-00012

[77] Ludgate, M.W., Fullen, D.R., Lee, J., Lowe, L., Bradford, C., Geiger, J., Schwartz, J. and Johnson, T.M. (2009) The Atypical Spitz Tumor of Uncertain Biologic Potential: A Series of 67 Patients from a Single Institution. Cancer, 115, 631-641. http://dx.doi.org/10.1002/cncr.24047

[78] Kim, J.Y., Choi, J.E., Ahn, H.H., Kye, Y.C. and Seo, S.H. (2012) A Case of Spitzoid Melanoma with Lymph Node Metastasis in a Child. Journal of Korean Medical Science, 27, 454-457. http://dx.doi.org/10.3346/jkms.2012.27.4.454

[79] Kamino, H. (2009) Spitzoid Melanoma. Clinics in Dermatology, 27, 545-555. http://dx.doi.org/10.1016/j.clindermatol.2008.09.013

[80] Murali, R., Sharma, R.N., Thompson, J.F., Stretch, J.R., Lee, C.S., Mccarthy, S.W. and Scolyer, R.A. (2008) Sentinel Lymph Node Biopsy in Histologically Ambiguous Melanocytic Tumors with Spitzoid Features (So-Called Atypical Spitzoid Tumors). Annals of Surgical Oncology, 15, 302-309. http://dx.doi.org/10.1245/s10434-007-9577-3

[81] Paradela, S., Fonseca, E., Pita, S., Kantrow, S.M., Goncharuk, V.N., Diwan, H. and Prieto, V.G. (2009) Spitzoid Melanoma in Children: Clinicopathological Study and Application of Immunohistochemistry as an Adjunct Diagnostic Tool. Journal of Cutaneous Pathology, 36, 740-752. http://dx.doi.org/10.1111/j.1600-0560.2008.01153.x

[82] Busam, K.J., Murali, R., Pulitzer, M., Mccarthy, S.W., Thompson, J.F., Shaw, H.M., et al. (2009) Atypical Spitzoid Melanocytic Tumors with Positive Sentinel Lymph Nodes in Children and Teenagers, and Comparison with Histologically Unambiguous and Lethal Melanomas. American Journal of Surgical Pathology, 33, 1386-1395. http://dx.doi.org/10.1097/PAS.0b013e3181ac1927

[83] Busam, K.J. and Pulitzer, M. (2008) Sentinel Lymph Node Biopsy for Patients with Diagnostically Controversial Spitzoid Melanocytic Tumors? Advances in Anatomic Pathology, 15, 253-262. http://dx.doi.org/10.1097/PAP.0b013e31818323ac

[84] Spatz, A., Calonje, E., Handfield-Jones, S. and Barnhill, R.L. (1999) Spitz Tumors in Children: A Grading System for Risk Stratification. Archives of Dermatology, 135, 282-285. http://dx.doi.org/10.1001/archderm.135.3.282

[85] Sepehr, A., Chao, E., Trefrey, B., Blackford, A., Duncan, L.M., Flotte, T.J., et al. (2011) Long-Term Outcome of Spitz-Type Melanocytic Tumors. Archives of Dermatology, 147, 1173-1179. http://dx.doi.org/10.1001/archdermatol.2011.170

[86] Gamblin, T.C., Edington, H., Kirkwood, J.M. and Rao, U.N. (2006) Sentinel Lymph Node Biopsy for Atypical Melanocytic Lesions with Spitzoid Features. Annals of Surgical Oncology, 13, 1664-1670. http://dx.doi.org/10.1245/s10434-006-9142-5

[87] Urso, C., Borgognoni, L., Saieva, C., Ferrara, G., Tinacci, G., Begliomini, B. and Reali, U.M. (2006) Sentinel Lymph Node Biopsy in Patients with “Atypical Spitz Tumors.” A Report on 12 Cases. Human Pathology, 37, 816-823. http://dx.doi.org/10.1016/j.humpath.2006.02.001

[88] Su, L.D., Fullen, D.R., Sondak, V.K., Johnson, T.M. and Lowe, L. (2003) Sentinel Lymph Node Biopsy for Patients with Problematic Spitzoid Melanocytic Lesions: A Report on 18 Patients. Cancer, 97, 499-507. http://dx.doi.org/10.1002/cncr.11074

[89] Smith, K.J., Barrett, T.L., Skelton III, H.G., Lupton, G.P. and Graham, J.H. (1989) Spindle Cell and Epithelioid Cell Nevi with Atypia and Metastasis (Malignant Spitz Nevus). American Journal of Surgical Pathology, 13, 931-939. http://dx.doi.org/10.1097/00000478-198911000-00003

[90] Cerroni, L., Barnhill, R., Elder, D., Gottlieb, G., Heenan, P., Kutzner, H., et al. (2010) Melanocytic Tumors of Uncertain Malignant Potential: Results of a Tutorial Held at the XXIX Symposium of the International Society of Dermatopathology in Graz, October 2008. American Journal of Surgical Pathology, 34, 314-326. http://dx.doi.org/10.1097/PAS.0b013e3181cf7fa0

[91] Hung, T., Piris, A., Lobo, A., Mihm Jr., M.C., Sober, A.J., Tsao, H., Tanabe, K.K. and Duncan, L.M. (2013) Sentinel Lymph Node Metastasis Is Not Predictive of Poor Outcome in Patients with Problematic Spitzoid Melanocytic Tumors. Human Pathology, 44, 87-94. http://dx.doi.org/10.1016/j.humpath.2012.04.019

[92] Zuckerman, R., Maier, J.P., Guiney Jr., W.B., Huntsman, W.T. and Mooney, E.K. (2001) Pediatric Melanoma: Confirming the Diagnosis with Sentinel Node Biopsy. Annals of Plastic Surgery, 46, 394-399. http://dx.doi.org/10.1097/00000637-200104000-00007

[93] Urso, C., Borgognoni, L., Doria, M., Tinacci, G. and Zini, E. (2009) Non-Sentinel Lymph Node Involvement in a Patient with an Atypical Spitz Tumor and a Positive Sentinel Node. Report of a Case and Review of the Literature. Jour- 
nal of Cutaneous Pathology, 36, 586-590. http://dx.doi.org/10.1111/j.1600-0560.2008.01080.x

[94] Wick, M.R. (2006) Melanocytic Lesions with Features of Spitz Nevus. Human Pathology, 37, 779-780. http://dx.doi.org/10.1016/j.humpath.2006.05.001

[95] Maduekwe, U.N., Hornicek, F.J., Springfield, D.S., Raskin, K.A., Harmon, D.C., Choy, E., et al. (2009) Role of Sentinel Lymph Node Biopsy in the Staging of Synovial, Epithelioid, and Clear Cell Sarcomas. Annals of Surgical Oncology, 16, 1356-1363. http://dx.doi.org/10.1245/s10434-009-0393-9

[96] Alcorn, K.M., Deans, K.J., Congeni, A., Sulkowski, J.P., Bagatell, R., Mattei, P. and Minneci, P.C. (2013) Sentinel Lymph Node Biopsy in Pediatric Soft Tissue Sarcoma Patients: Utility and Concordance with Imaging. Journal of Pediatric Surgery, 48, 1903-1906. http://dx.doi.org/10.1016/j.jpedsurg.2013.04.013

[97] Andreou, D., Boldt, H., Werner, M., Hamann, C., Pink, D. and Tunn, P.U. (2013) Sentinel Node Biopsy in Soft Tissue Sarcoma Subtypes with a High Propensity for Regional Lymphatic Spread-Results of a Large Prospective Trial. Annals of Oncology, 24, 1400-1405. http://dx.doi.org/10.1093/annonc/mds650

[98] Nishida, Y., Tsukushi, S., Yamada, Y., Shimoyama, Y., Shido, Y., Wasa, J. and Ishiguro, N. (2011) Recurrent Alveolar Rhabdomyosarcoma with Prior Surgery and Radiotherapy: Altered Lymphatic Drainage Limits the Reliability of Sentinel Lymph Node Biopsy. Journal of Pediatric Hematology/Oncology, 33, e26-e28. http://dx.doi.org/10.1097/MPH.0b013e3181faf857

[99] Riad, S., Griffin, A.M., Liberman, B., Blackstein, M.E., Catton, C.N., Kandel, R.A., et al. (2004) Lymph Node Metastasis in Soft Tissue Sarcoma in an Extremity. Clinical Orthopaedics and Related Research, 426, 129-134. http://dx.doi.org/10.1097/01.blo.0000141660.05125.46

[100] Behranwala, K.A., A’Hern, R., Omar, A.M. and Thomas, J.M. (2004) Prognosis of Lymph Node Metastasis in Soft Tissue Sarcoma. Annals of Surgical Oncology, 11, 714-719. http://dx.doi.org/10.1245/ASO.2004.04.027

[101] Billingsley, K.G., Burt, M.E., Jara, E., Ginsberg, R.J., Woodruff, J.M., Leung, D.H. and Brennan, M.F. (1999) Pulmonary Metastases from Soft Tissue Sarcoma: Analysis of Patterns of Diseases and Postmetastasis Survival. Annals of Surgery, 229, 602-610. http://dx.doi.org/10.1097/00000658-199905000-00002

[102] Fong, Y., Coit, D.G., Woodruff, J.M. and Brennan, M.F. (1993) Lymph Node Metastasis from Soft Tissue Sarcoma in Adults. Analysis of Data from a Prospective Database of 1772 Sarcoma Patients. Annals of Surgery, 217, 72-77. http://dx.doi.org/10.1097/00000658-199301000-00012

[103] Daigeler, A., Kuhnen, C., Moritz, R., Stricker, I., Goertz, O., Tilkorn, D., et al. (2009) Lymph Node Metastases in Soft Tissue Sarcomas: A Single Center Analysis of 1,597 Patients. Langenbeck’s Archives of Surgery, 394, 321-329. http://dx.doi.org/10.1007/s00423-008-0371-x

[104] Deenik, W., Mooi, W.J., Rutgers, E.J., Peterse, J.L., Hart, A.A. and Kroon, B.B. (1999) Clear Cell Sarcoma (Malignant Melanoma) of Soft Parts: A Clinicopathologic Study of 30 Cases. Cancer, 86, 969-975. http://dx.doi.org/10.1002/(SICI)1097-0142(19990915)86:6<969::AID-CNCR11>3.0.CO;2-Z

[105] Mcmulkin, H.M., Yanchar, N.L., Fernandez, C.V. and Giacomantonio, C. (2003) Sentinel Lymph Node Mapping and Biopsy: A Potentially Valuable Tool in the Management of Childhood Extremity Rhabdomyosarcoma. Pediatric Surgery International, 19, 453-456. http://dx.doi.org/10.1007/s00383-003-0956-y

[106] Neville, H.L., Raney, R.B., Andrassy, R.J. and Cooley, D.A. (2000) Multidisciplinary Management of Pediatric SoftTissue Sarcoma. Oncology (Williston Park), 14, 1471-1481.

[107] National Cancer Institute at the National Institutes of Health. Childhood Rhabdomyosarcoma Treatment (PDQ $\left.{ }^{\circledR}\right)$. http://www.cancer.gov

[108] National Cancer Institute at the National Institutes of Health. Childhood Soft Tissue Sarcoma Treatment (PDQ $\left.{ }^{\circledR}\right)$. http://www.cancer.gov

[109] Flynn, L.W., Park, J., Patil, S.M., Cody III, H.S. and Port, E.R. (2008) Sentinel Lymph Node Biopsy Is Successful and Accurate in Male Breast Carcinoma. Journal of the American College of Surgeons, 206, 616-621. http://dx.doi.org/10.1016/j.jamcollsurg.2007.11.005

[110] Pacella, S.J., Lowe, L., Bradford, C., Marcus, B.C., Johnson, T. and Rees, R. (2003) The Utility of Sentinel Lymph Node Biopsy in Head and Neck Melanoma in the Pediatric Population. Plastic \& Reconstructive Surgery, 112, 12571265. http://dx.doi.org/10.1097/01.PRS.0000080728.51964.4A

[111] Palmer 3rd, P.E., Warneke, C.L., Hayes-Jordan, A.A., Herzog, C.E., Hughes, D.P., Lally, K.P. and Austin, M.T. (2013) Complications in the Surgical Treatment of Pediatric Melanoma. Journal of Pediatric Surgery, 48, 1249-1253. http://dx.doi.org/10.1016/j.jpedsurg.2013.03.018 
Scientific Research Publishing (SCIRP) is one of the largest Open Access journal publishers. It is currently publishing more than 200 open access, online, peer-reviewed journals covering a wide range of academic disciplines. SCIRP serves the worldwide academic communities and contributes to the progress and application of science with its publication.

Other selected journals from SCIRP are listed as below. Submit your manuscript to us via either submit@scirp.org or Online Submission Portal.
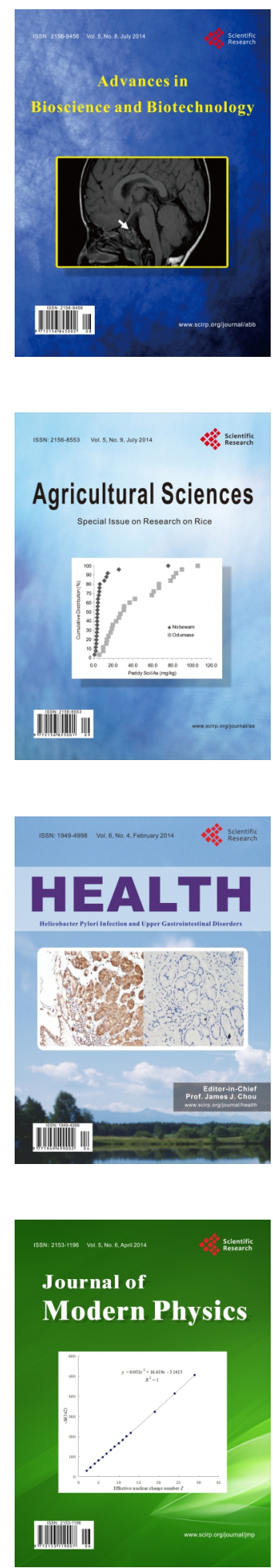
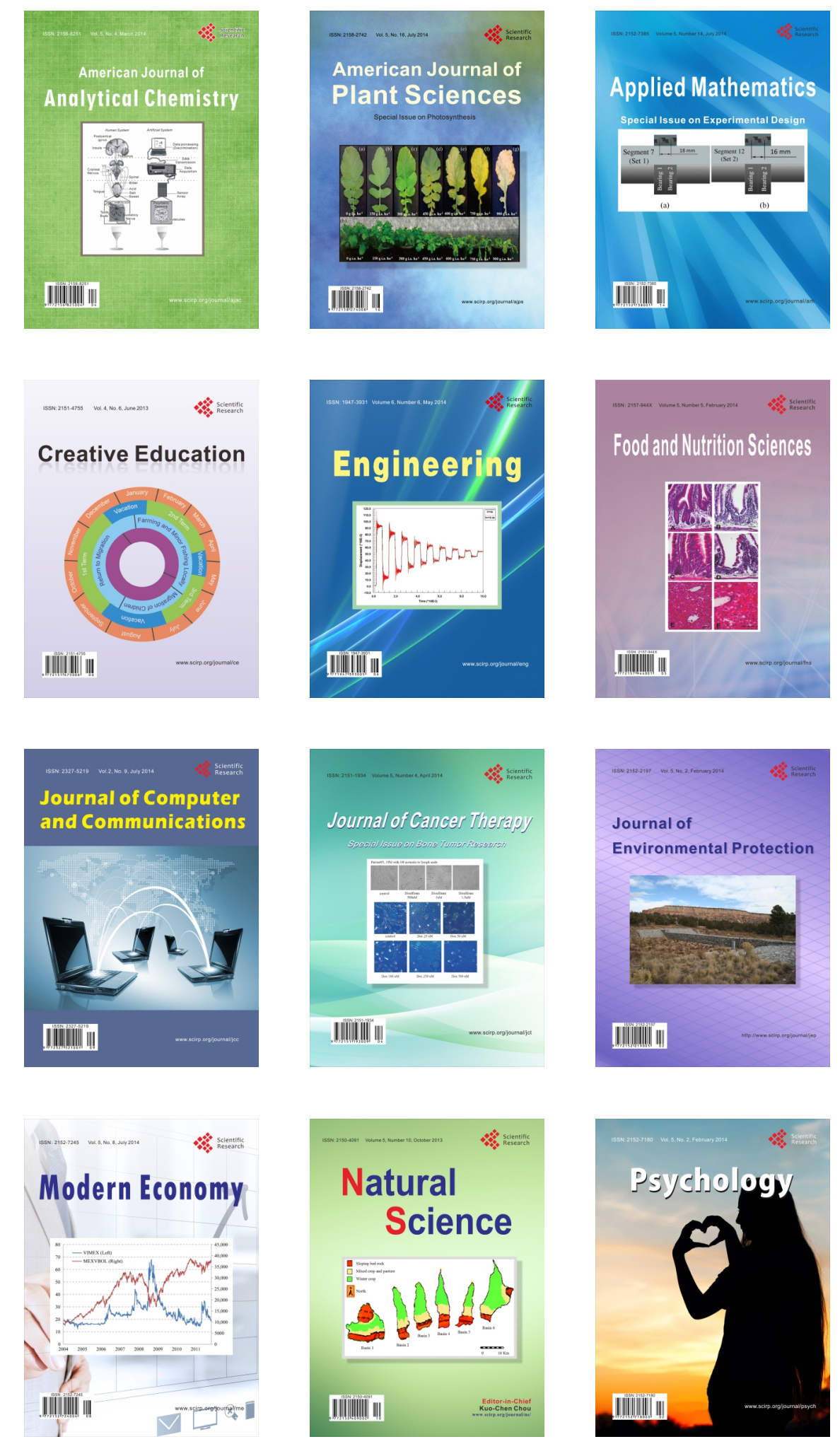